\title{
Transient versus Permanent Congenital Hypothyroidism after the Age of 3 Years in Infants Detected on the First versus Second Newborn Screening Test in Oregon, USA
}

\author{
George A. Ford ${ }^{a}$ Sara Denniston $^{b}$ David Sesser $^{b}$ Michael R. Skeels $^{b}$ \\ Stephen H. LaFranchi ${ }^{a}$ \\ aPediatric Endocrinology, Oregon Health and Science University, Portland, Oreg., and ${ }^{\mathrm{b}}$ Oregon State Public Health \\ Laboratory, Hillsboro, Oreg., USA
}

\section{Key Words}

Congenital hypothyroidism · Newborn screening .

Transient vs. permanent congenital hypothyroidism .

Second routine screening

\begin{abstract}
Background/Aims: The newborn screening (NBS) program in Oregon, USA, collects two routine specimens in all infants. The aim of our study was to determine the incidence of permanent versus transient congenital hypothyroidism $(\mathrm{CH})$ in infants detected on the first versus second screening test. Methods: Thyroid function was determined in infants after the age of 3 years diagnosed with $\mathrm{CH}$ and born in Oregon between 2005 and 2011. Permanent hypothyroidism was defined as a TSH rise $>10 \mathrm{mIU} / \mathrm{ml}$ after the first year on treatment or a TSH rise $>6 \mathrm{mlU} / \mathrm{ml}$ with temporary discontinuation of I-thyroxine after the age of 3 years. Results: Of the cases detected on the first test, 72 of 87 (83\%) were permanent and 15 of 87 (17\%) were transient, while of the cases detected on the second test, 5 of $22(23 \%)$ were permanent and 17 of $22(77 \%)$ were transient (OR 16.3, $p<0.001)$. There was a female preponderance detected on the first screen
\end{abstract}

\section{KARGER}

(๑) 2016 S. Karger AG, Basel

E-Mail karger@karger.com

www.karger.com/hrp versus a male preponderance on the second screen. Blood spot and serum thyroid function tests at diagnosis, before treatment, were not meaningfully different between the two groups. The mean l-thyroxine dose at the age of 3 years was greater on the first screen: 61.2 versus $36.6 \mu \mathrm{g} /$ day. Conclusions: Infants detected on the second NBS specimen have a higher incidence of transient $\mathrm{CH}$.

(c) 2016 S. Karger AG, Basel

\section{Introduction}

Congenital hypothyroidism $(\mathrm{CH})$ has a reported incidence of 1:2,000 to 1:4,000, is the most common disorder detected on newborn screening (NBS), and represents one of the most common preventable causes of intellectual disability [1]. Diagnosis and treatment of $\mathrm{CH}$ rely on early detection via the NBS due to lack of initial early clinical manifestations. The chief objective of the current screening programs is to accurately detect infants with primary $\mathrm{CH}$. Primary $\mathrm{CH}$ is manifested by a low serum total thyroxine (T4 or free $\mathrm{T} 4$ ) concentration and a high serum thyrotropin (TSH) concentration. Testing strate- 
gies in the United States vary by state, but they involve either a primary TSH test or a T4-reflex TSH test algorithm, with some programs employing combined T4 and TSH testing [2]. The Northwest Regional Screening Program (NWRSP), coordinated in Oregon, employs a primary T4, reflex TSH approach for which an initial specimen is obtained in the newborn period and a second routine specimen is collected at approximately $2-4$ weeks of age in all infants. Oregon is one of few states that collect a second routine specimen for all births. Some data regarding the potential benefits of obtaining two routine specimens to screen for $\mathrm{CH}$ has been previously published. In 1985, the NWRSP reported that 19 infants with $\mathrm{CH}$ were detected on the second screen over a 9.5-year period; these cases represented $10 \%$ of all infants diagnosed with $\mathrm{CH}$, yielding an incidence of 1:25,505 [3]. The effectiveness of collecting a second routine screening test was also evaluated by the Colorado NBS Program, which reported that in the absence of a second screen, a diagnosis of $\mathrm{CH}$ would have been missed in 1 infant per 11,111 births [4]. These studies from the NWRSP and Colorado did not provide information regarding differences between those infants diagnosed on the first versus second NBS as it relates to outcome. These differences include: permanence versus transience with consideration for prematurity and sickness as a known variable influencing permanence or transience of $\mathrm{CH}$ [5]; potential differences in the severity of hypothyroidism at diagnosis; differences in thyroid hormone dosing in the first 3 years of life, and whether patients were trialed off therapy after the age of 3 years where appropriate in accordance with the American Academy of Pediatrics (AAP) and European Society for Paediatric Endocrinology (ESPE) guidelines $[6,7]$. The primary aim of our study was to examine the natural history of thyroid function in cases detected on the first versus the second NBS test by determining whether infants had permanent or transient hypothyroidism at (or after) 3 years of age. The secondary aims sought to determine potential differences in severity of hypothyroidism at diagnosis, differences in thyroid dosing in the first 3 years of life, and documentation of whether patient's were appropriately trialed off therapy in accordance with the AAP and ESPE guidelines.

\section{Methods}

Oregon employs a primary T4-reflex TSH test approach, with collection of two routine specimens for all births. An initial specimen (whole blood spotted on filter paper) is obtained $24-72 \mathrm{~h}$ after birth and a second specimen is collected at approximately 2-4 weeks of age. Testing is performed by the Oregon State Public Health Laboratory. Infants with a blood spot total T4 of $<10$ th percentile on either the first or second routine NBS are flagged as abnormal and a reflex TSH is performed. If the blood spot TSH is elevated by $>25 \mathrm{mIU} / \mathrm{l}$ (serum units), confirmatory serum TSH and free $\mathrm{T} 4$ are measured. Infants detected on the first routine NBS test (blood spot T4 of $<10$ th percentile, elevated TSH level), followed by serum testing showing a low free T4 and elevated TSH level, were categorized as being detected on the first routine NBS test. Infants who passed their first NBS test (T4 of $>10$ th percentile, therefore no TSH measured), but who were then detected on the second routine screening test with a blood spot T4 of $<10$ th percentile and elevated TSH level, with positive confirmatory serum testing, were categorized as being detected on the second NBS test. Our study population consisted of patients born in the state of Oregon between 2005 and 2011 with $\mathrm{CH}$ detected on either the first or second NBS test.

We used various means to try to locate these patients, now all $\geq 3$ years of age, to obtain information to be used in the study. Demographic information, including gender, ethnicity/race, length of gestation, and birth weight, was obtained from the Oregon State Public Health Laboratory records. Screening blood spot and confirmatory (pretreatment) serum thyroid function test results were obtained from the NWRSP. Thyroid function test results measured during monitoring of treatment and l-thyroxine dosing information was obtained from the electronic medical record of the Oregon Health and Science University (OHSU) for those cases followed at OHSU and from letters and subsequent telephone calls to the primary care physicians (PCPs) for other cases (all patients in this study have an established relationship with the OHSU Pediatric Endocrinology Division dating from initial detection and treatment). When the patient's current PCP could not be identified, the patient's families were contacted via letter and as needed by phone to determine the name and contact information of their treating physician.

Using criteria published by the AAP and ESPE guidelines [5, 6], patients were categorized as having permanent $\mathrm{CH}$ in one of two ways: (1) if they had a serum TSH rise $>10 \mathrm{mIU} / \mathrm{l}$ after the first year of life while on l-thyroxine treatment, as might have occurred as they outgrew a dose or with poor compliance, and (2) if they were trialed off l-thyroxine treatment after the age of 3 years and had a subsequent TSH $>6 \mathrm{mIU} / \mathrm{l}$. $\mathrm{CH}$ was considered transient if the patient was trialed off therapy after the age of 3 years and had normal thyroid function tests 1 month or more after discontinuation of 1-thyroxine and remained off therapy. Patients on 1-thyroxine therapy at the age of 3 years, but who had not had a TSH rise $>10 \mathrm{mU} / \mathrm{l}$ on treatment, and who were not trialed off therapy, were categorized as 'indeterminate'. For indeterminate cases not under our care, where transient hypothyroidism was suspected, including for example, a patient never requiring a dosage increase, the patient's PCP was contacted by phone and encouraged to consider a trial off 1-thyroxine. However, a certain number of cases were never trialed off treatment and so remained classified as indeterminate. Thyroid imaging either by ultrasound or radioisotope scan was not included in the scope of diagnostic workup in Oregon, either during the newborn period or at re-evaluation after 3 years of age. This study was reviewed and approved by the OHSU Institutional Review Board.

Statistical comparison of the demographic characteristics of cases detected on the first versus second NBS test was performed 


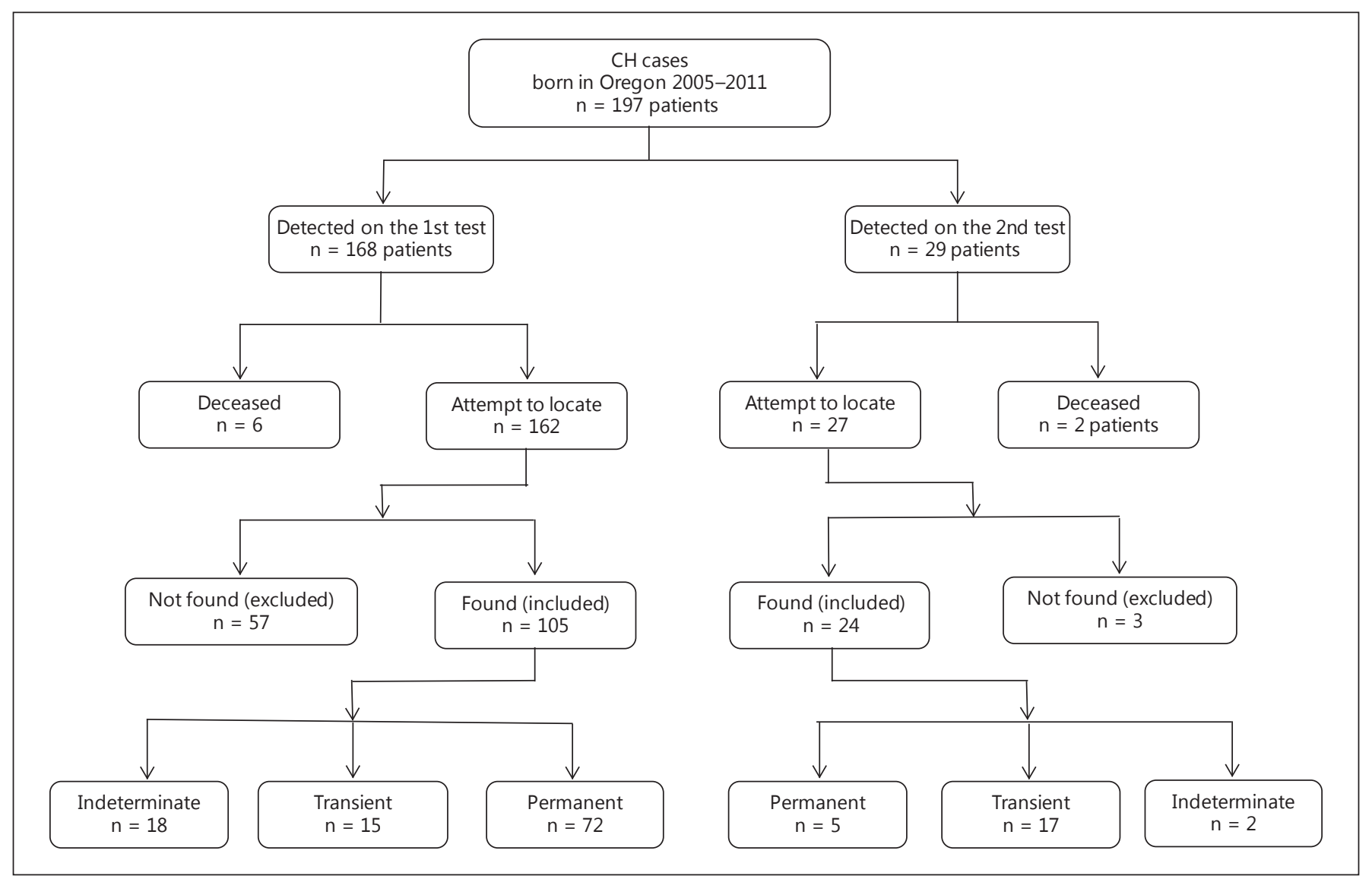

Fig. 1. CH cases born in Oregon between 2005 and 2011, patients detected on the first and second screening test, number of patients found and included for study, and thyroid function at the age of 3 years.

using $\chi^{2}$, Fisher's exact test, or t test, where applicable. A test of the null hypothesis that the probability of having transient $\mathrm{CH}$ was the same in cases detected on the first and second NBS test was performed using Fisher's exact test. Log transformation of the blood spot total T4 and TSH, serum free T4, and TSH allowed comparison of the geometric means by Welch's t test. Comparison of the mean dose of l-thyroxine at the age of 3 years in patients detected on the first versus second NBS test was performed by a two-sided $t$ test with unequal variances.

\section{Results}

Over the 7-year period between 2005 and 2011, 197 babies with $\mathrm{CH}$ were detected in the state of Oregon from 331,688 total births, with an incidence of 1:1,684. Of these 197 patients, 168 were found on the first NBS test $(1: 1,984)$, while 29 were detected on the second routine NBS test $(1: 11,438)$. Over this 7-year period, $14.7 \%$ of $\mathrm{CH}$

Transient versus Permanent $\mathrm{CH}$ in Infants after the Age of 3 Years cases were detected as a result of the second routine screening test. Six patients on the first screen and 2 patients on the second screen were deceased, leaving 162 patients on the first screen and 27 patients on the second screen for potential inclusion in our study (fig. 1).

We were able to find follow-up information on 105 patients aged $\geq 3$ years detected on the first test $(65 \%)$ and 24 patients detected on the second routine test (89\%) (fig. 1). Of the infants with $\mathrm{CH}$ detected on the first NBS, $69 \%$ of cases were permanent, $14 \%$ were transient, and $17 \%$ were indeterminate (fig. $2 \mathrm{a}$ ). Of the infants with $\mathrm{CH}$ detected on the second NBS, $71 \%$ of cases were transient, $21 \%$ were permanent, and $8 \%$ were indeterminate (fig. 2b).

A comparison of the demographic characteristics between patients located after the age of 3 years detected on the first specimen versus those detected on the second specimen did not demonstrate any significant differences 
Table 1. Comparison of demographic characteristics of patients detected on the first versus the second specimen $(n=129)$
Fig. 2. a Percentage of permanent $(n=72)$, transient $(\mathrm{n}=15)$, and indeterminate $(\mathrm{n}=$ 18) $\mathrm{CH}$ cases on the first NBS (total $\mathrm{n}=$ 105). b Percentage of permanent $(n=5)$, transient $(\mathrm{n}=17)$, and indeterminate $(\mathrm{n}=$ 2) $\mathrm{CH}$ cases on the second NBS $(\mathrm{n}=24)$.

\begin{tabular}{|c|c|c|c|c|}
\hline & & $\begin{array}{l}\text { First specimen, } \\
\mathrm{n}(\%)\end{array}$ & $\begin{array}{l}\text { Second specimen, } \\
\mathrm{n}(\%)\end{array}$ & $\mathrm{p}$ value \\
\hline Patients & & 105 & 24 & \\
\hline Female & & $63(60)$ & $11(46)$ & 0.255 \\
\hline \multicolumn{5}{|l|}{ Race/ethnicity } \\
\hline Caucasian & $72.7^{\mathrm{a}}$ & $50(48)$ & $16(67)$ & \\
\hline Black & $3.7^{\mathrm{a}}$ & $4(4)$ & $1(4)$ & \\
\hline Native American & $1.9^{\mathrm{a}}$ & $2(2)$ & $0(0)$ & \\
\hline Asian/Pacific Islander & $5.2^{\mathrm{a}}$ & $11(10)$ & $4(17)$ & \\
\hline Unknown & $16.5^{\mathrm{a}}$ & $38(36)$ & $3(12)$ & 0.152 \\
\hline Hispanic ethnicity & & $27(26)$ & $2(8)$ & 0.064 \\
\hline Term $(>37 \text { weeks })^{b}$ & & $84(89)$ & $17(81)$ & 0.470 \\
\hline Preterm (<37 weeks) & & $11(11)$ & 4 (19) & 0.724 \\
\hline Mean birth weight $\pm S D, g$ & & $3,183 \pm 721$ & $3,036 \pm 930$ & 0.453 \\
\hline
\end{tabular}

Values are $\mathrm{n}(\%)$ except where otherwise indicated.

a Percentages of race/ethnicity from the entire Oregon birth population during the period between 2005 and $2011(\mathrm{n}=331,688)$. Additionally, 22.1\% of the birth population identified themselves as having a Hispanic ethnicity.

${ }^{\mathrm{b}}$ Gestational age is not available for some cases detected on the first $(\mathrm{n}=10)$ and second specimen $(n=3)$.

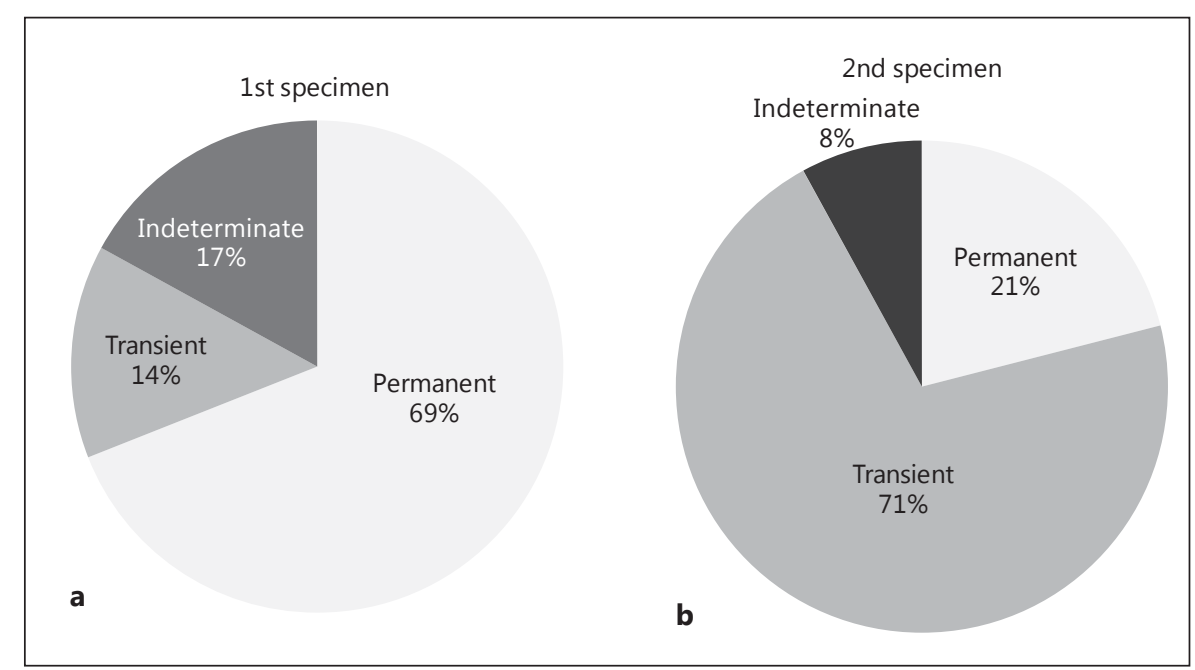

in gender (despite female preponderance in the first specimen group), race, Hispanic ethnicity, gestational age, or birth weight (table 1). In addition, we did not find any significant differences in these demographic characteristics between infants found $(n=129)$ and those for whom we were unable to locate follow-up information after the age of 3 years $(n=60)$. Of note, $\mathrm{CH}$ cases diagnosed on the first screen had a female to male preponderance of 1.5:1. However, this was not the case for infants diagnosed on the second screen, for which there was a slight male to female preponderance of 1.2:1. A comparison of race/ethnicity for infants detected on the first versus second specimen, along with data on the Oregon birth population, is presented in table 1. Asian/Pacific Islanders appeared to be disproportionally affected making up $10 \%$ of $\mathrm{CH}$ cases on the first screen and $17 \%$ on the second screen as compared to $5.2 \%$ of the general birth population. Caucasians made up less than the expected number of cases for the 
Table 2. Percentage of permanent versus transient $\mathrm{CH}$ in cases with thyroid function determined after the age of 3 years

\begin{tabular}{llll}
\hline $\mathrm{CH}$ & First screen & Second screen & Total \\
\hline $\begin{array}{l}\text { Permanent } \\
\text { Transient }\end{array}$ & $15(83)$ & $5(23)$ & $77(71)$ \\
\hline Total & $87(100)$ & $22(100)$ & $109(100)$ \\
\hline \multicolumn{4}{c}{$\begin{array}{l}\text { Values are n }(\%) . \\
\text { a Infants detected on the second NBS are more likely to have }\end{array}$} \\
$\begin{array}{l}\text { transient CH compared to those on the first screen. OR }=16.3, \\
\mathrm{p}<0.001 .\end{array}$ \\
\hline
\end{tabular}

population on the first screen (48\%), though the percent affected on the second screen (67\%) was closer to the $72.7 \%$ present in the general birth population. Hispanics, who made up $22.1 \%$ of the general birth population, were similarly affected on the first screen but appeared to be under represented on the second screen ( 26 vs. $8 \%$ ). The percentages of $\mathrm{CH}$ in Blacks and Native Americans were close to the expected general population norms.

The mean (SD) birth weight was similar in infants detected on the first and second screen (table 1). Of the 105 cases detected on the first screen, 8 were $<2,500 \mathrm{~g}, 2$ were $<1,500 \mathrm{~g}$, and 1 was $<1,000 \mathrm{~g}$, while of the 24 cases detected on the second screen, 2 were $<2,500 \mathrm{~g}$, none were $<1,500 \mathrm{~g}$, and 1 was $<1,000 \mathrm{~g}$ (one premature infant birth weight was unknown). The mean (SD) gestational age was 38.8 (2.6) weeks versus 38.3 (2.8) weeks in infants detected on the first and second screen, respectively. Of the 105 cases detected on the first screen, 6 were in the gestational age group of 32-37 weeks, 5 were $28-32$ weeks, and none were $<28$ weeks. Of the 24 detected on the second screen, 3 were in the gestational age group pf $32-37$ weeks, 1 was $28-32$ weeks, and none were $<28$ weeks. The prevalence of preterm birth detected on the second screen was higher than on the first screen: 4 of 24 (19\%) versus 11 of $105(11 \%)$, but this difference was not significant (table 1). Of premature infants with $\mathrm{CH}$ detected on the first screen, 3 of $11(27 \%)$ were transient, 2 of $11(18 \%)$ were permanent, and 6 of $11(55 \%)$ were indeterminate. Of premature infants with $\mathrm{CH}$ detected on the second screen 1 of $4(25 \%)$ were transient, 2 of $4(50 \%)$ were permanent, and 1 of $4(25 \%)$ were indeterminate.

For cases in which we were able to establish the thyroid function, our data demonstrated a higher rate of permanent $\mathrm{CH}$ in infants identified on the first versus second NBS (83 vs. 23\%). Conversely, infants detected on the sec-

Transient versus Permanent $\mathrm{CH}$ in Infants after the Age of 3 Years ond routine NBS were significantly more likely to have a transient form of $\mathrm{CH}$ compared to those on the first screen (77 vs. $17 \%$, OR 16.3, p < 0.001) (table 2).

By definition, the blood spot $\mathrm{T} 4$ was low in infants detected on the first screen and normal in the first test in cases detected on the second routine screen (4.63 vs. 15.1 $\mu \mathrm{g} / \mathrm{dl})$. However, the abnormal blood spot total T4 leading to the diagnosis did not differ between infants detected on the first and second screen (geometric mean 4.63 vs. 5.09 $\mu \mathrm{g} / \mathrm{dl}, \mathrm{p}=0.55$ ) (table 3 ). The mean screening TSH was higher in infants detected on the first versus second NBS (164 vs. $53.2 \mathrm{mIU} / \mathrm{l}, \mathrm{p}=0.003$ ); however, as over half of the TSH values on the first screen were reported at $>200 \mathrm{mIU} / \mathrm{l}$ (vs. an actual number on the first screen result), this statistical finding did not appear to represent a meaningful difference. The skewed nature of the screening TSH values is further supported by data analysis demonstrating a greater likelihood of a blood spot TSH above $200 \mathrm{mIU} / \mathrm{l}$ on the first screen $(\mathrm{OR}=6.8, \mathrm{CI} 2.1-25.5)$ (table 3$)$. Serum free T4 at diagnosis, prior to treatment did not differ between infants detected on the first and second screen (geometric mean 0.61 vs. 0.64 ng/dl, p = 0.785) (table 3). Further, serum TSH prior to treatment did not differ between infants identified on the first and second screen (log-transformed means 119.8 vs. $85.7 \mathrm{mIU} / \mathrm{l}, \mathrm{p}=0.081$ ) (table 3 ).

Of the five permanent $\mathrm{CH}$ cases detected on the second screen, 3 patients had mild (subclinical) permanent $\mathrm{CH}$ with TSH values of $8.65,8.72$, and $9.02 \mathrm{mIU} / \mathrm{l}$ after a trial off l-thyroxine therapy, respectively, 1 case demonstrated moderate permanent $\mathrm{CH}$ with a TSH rise $>10 \mathrm{mIU} / \mathrm{l}$ (the highest TSH rise was $18 \mathrm{mIU} / \mathrm{l}$ ) while on treatment, which required subsequent l-thyroxine dose increases, and 1 case demonstrated significant permanent $\mathrm{CH}$ with a TSH of $97.2 \mathrm{mIU} / \mathrm{l}$ after a trial off l-thyroxine therapy (table 4).

The mean thyroxine dose was higher at 3 years in patients detected on the first screen, $61.2 \mu \mathrm{g}(\sim 4 \mu \mathrm{g} / \mathrm{kg} /$ day $)$ versus $36.6 \mu \mathrm{g}(\sim 2 \mu \mathrm{g} / \mathrm{kg} /$ day $)$ for patients detected on the second screen $(\mathrm{p}<0.001)$.

\section{Discussion}

This study provides unique information on the natural history of thyroid function in infants who appear to have onset of hypothyroidism prenatally versus onset in the early neonatal period. Prior to this study, the rate of permanent versus transient hypothyroidism detected on two routine screening tests collected at two different time periods in a full birth population was unknown. Our evalu- 
Table 3. Screening blood spot total T4 and TSH and confirmatory serum free T4 and TSH in cases detected on the first and second screening test ${ }^{\mathrm{a}}$

\begin{tabular}{|c|c|c|c|c|c|c|}
\hline & $\begin{array}{l}\text { First screen } \mathrm{T} 4 \text {, } \\
\mu \mathrm{g} / \mathrm{dl}\end{array}$ & $\begin{array}{l}\text { First screen TSH, } \\
\mathrm{mIU} / \mathrm{ml}\end{array}$ & $\begin{array}{l}\text { Second screen } \mathrm{T} 4 \text {, } \\
\mu \mathrm{g} / \mathrm{dl}\end{array}$ & $\begin{array}{l}\text { Second screen TSH, } \\
\mathrm{mIU} / \mathrm{ml}\end{array}$ & $\begin{array}{l}\text { Serum free } \mathrm{T} 4 \text {, } \\
\mathrm{ng} / \mathrm{dl}\end{array}$ & $\begin{array}{l}\text { Serum TSH, } \\
\mathrm{mIU} / \mathrm{ml}\end{array}$ \\
\hline Age-normal reference range & $>10 \%(\sim 8$ to 18$)$ & $<25$ & $>10 \%(\sim 6$ to 15$)$ & $<25$ & 0.8 to 2.2 & 0.5 to 5.8 \\
\hline First screen $(n=87)$ & $4.63(3.10 \text { to } 6.50)^{\mathrm{b}}$ & $164(100 \text { to } 200)^{c}$ & n./a. & n./a. & $0.61(0.39$ to 0.81$)$ & $119.8(100$ to 150$)$ \\
\hline Second screen $(n=22)$ & $15.1(12.75$ to 17.45$)$ & n./a. & 5.09 (3.84 to 7.08$) \mathrm{b}$ & $53.2(37.5 \text { to } 99)^{c}$ & $0.64(0.47$ to 0.80$)$ & $85.7(60.4$ to 113.8$)$ \\
\hline$p$ value & - & - & - & - & 0.785 & 0.081 \\
\hline
\end{tabular}

Values are log-transformed means, with 25th-75th percentiles in parentheses. n./a. = Not applicable.

a To convert T4 from $\mu \mathrm{g} / \mathrm{dl}$ to $\mathrm{nmol} / \mathrm{l}$ or free $\mathrm{T} 4 \mathrm{from} \mathrm{ng} / \mathrm{dl}$ to $\mathrm{pmol} / \mathrm{l}$, multiply by 12.87 . $\mathrm{b}$ There was no significant difference between screening total T4 values on the first specimen (cases detected on the first screen) versus second specimen (cases detected on the second screen) $(\mathrm{p}=0.549)$. ${ }^{\mathrm{c}}$ There was a significant $(\mathrm{p}=0.003)$ though statistically not meaningful difference between screening TSH on the first versus second specimen (see text for explanation).

Table 4. Individual blood spot and serum thyroid function test results in 5 infants detected by second screening and in whom permanent $\mathrm{CH}$ was confirmed after the age of 3 years ${ }^{1}$

\begin{tabular}{|c|c|c|c|c|c|c|c|c|c|c|}
\hline Patients, n & $\begin{array}{l}\text { Age at 1st } \\
\text { specimen, } \\
\text { days }\end{array}$ & $\begin{array}{l}\text { 1st } \\
\text { screen T4, } \\
\mu \mathrm{g} / \mathrm{dl}\end{array}$ & $\begin{array}{l}\text { 1st screen } \\
\text { TSH, mIU/ } \\
\mathrm{ml}\end{array}$ & $\begin{array}{l}\text { Age at } 2 \text { nd } \\
\text { specimen, } \\
\text { days }\end{array}$ & $\begin{array}{l}\text { 2nd } \\
\text { screen T4, } \\
\mu \mathrm{g} / \mathrm{dl}\end{array}$ & $\begin{array}{l}\text { 2nd } \\
\text { screen TSH, } \\
\mathrm{mIU} / \mathrm{ml}\end{array}$ & $\begin{array}{l}\text { Serum free } \\
\mathrm{T} 4, \mathrm{ng} / \mathrm{dl}^{2}\end{array}$ & $\begin{array}{l}\text { Serum TSH, } \\
\mathrm{mIU} / \mathrm{ml}^{2}\end{array}$ & $\begin{array}{l}\text { Serum free } \\
\mathrm{T} 4>3 \text { years, } \\
\text { ng/dl }\end{array}$ & $\begin{array}{l}\text { Serum } \\
\text { TSH >3 } \\
\text { years, } \\
\mathrm{mIU} / \mathrm{ml}\end{array}$ \\
\hline $\begin{array}{l}\text { Age-normal } \\
\text { reference range }\end{array}$ & & $\begin{array}{l}>10 \% \\
(\sim 8 \text { to } 18)\end{array}$ & $<25$ & & $\begin{array}{l}>10 \% \\
(\sim 6 \text { to } 15)\end{array}$ & $<25$ & 0.8 to 2.2 & 0.5 to 5.8 & 0.8 to 2.2 & 0.5 to 5.8 \\
\hline 1 & 1 & 13.5 & n./a. & 14 & 7.2 & 46.6 & 0.66 & 79.6 & 1.0 & 8.65 \\
\hline 2 & 2 & 14.5 & n./a. & 15 & 3.1 & 83.8 & 0.39 & 196.3 & 0.9 & 8.72 \\
\hline 3 & 2 & 12.7 & n./a. & 16 & 6.7 & 55.1 & 0.60 & 60 & 0.9 & 9.02 \\
\hline 4 & 3 & 8.7 & n./a. & 30 & 4.3 & 102.8 & 0.47 & $>100$ & 0.7 & 34.8 \\
\hline 5 & 1 & 12.8 & n./a. & 19 & 6.1 & 161.5 & 0.40 & 206.8 & 0.8 & 97.2 \\
\hline
\end{tabular}

n./a. = Not applicable.

${ }^{1}$ To convert T4 from $\mu \mathrm{g} / \mathrm{dl}$ to $\mathrm{nmol} / \mathrm{l}$ or free $\mathrm{T} 4$ from $\mathrm{ng} / \mathrm{dl}$ to $\mathrm{pmol} / \mathrm{l}$, multiply by $12.87 .{ }^{2}$ Before treatment.

ation after 3 years of age found that the majority of infants detected on the first, early screening test had permanent $\mathrm{CH}$, while the majority of infants detected on the later, second screening test had transient $\mathrm{CH}$.

The previous study from the NWRSP, undertaken in babies born between 1975 and 1985, reported that $10 \%$ of $\mathrm{CH}$ cases were detected on the second screen, with an incidence of $1: 25,505$ [3], compared to detection of $14.7 \%$ of all $\mathrm{CH}$ cases with an incidence of 1:11,438 in our current study. As noted above, Maniatis et al. [4] reported a detection rate of $1: 11,111 \mathrm{CH}$ cases on the second screen in Colorado, USA, similar to the rate in our current study. Both the 1985 NWRSP [3] and the study by Maniatis et al. [4] noted a 2:1 female to male ratio for infants detected on the first screen, with slightly more boys identified on the second screen. Our current study confirmed these trends; the higher female preponderance on the first screen may reflect the higher rate of permanence on the first screen and known high prevalence of $\mathrm{CH}$ in girls.
The explanation for the apparent differences in sex ratios for cases detected on the first versus second screening test is unknown, but it may be a clue to the etiology underlying the permanent versus transient $\mathrm{CH}$ in these cases. A further clue may be provided by the race/ethnicity data. We found a higher percentage of Asian/Pacific Islander cases on the second screen. Although the number of cases is small, similar findings were reported in a much larger study by Shapira et al. [8], where the detection rate of Asian/Pacific Islanders was twice as common in twoscreen states versus one-screen states (1:968 vs. 1:1,586).

Although the prevalence of preterm births detected on the second screen appeared higher, this difference was not significant. Maniatis et al. [4] reported that infants detected on the second screen were not more premature or lower birth weight than those identified on the first screen. Our study demonstrated similar birth weights between cases detected on the first and second screening test. Previous studies have reported 'delayed TSH elevation' in 
preterm neonates, with detection on a second screening test [9], and a higher rate of transient $\mathrm{CH}$ in preterm infants [10], but preterm birth/low birth weight did not appear to be significant factors in our current study.

In the previous NWRSP report, infants detected on the second screening test had higher blood spot T4 levels (7.02 vs. $3.82 \mu \mathrm{g} / \mathrm{dl})$ and lower TSH concentrations (34.5 vs. $245 \mathrm{mIU} / \mathrm{l}$ ) as compared to infants detected on the first test [3]. These results were consistent with a milder form of hypothyroidism, perhaps explaining why these infants passed their first NBS test, only to be detected on the second test. This difference was not found in the current study. There have not been any significant changes in the screening 'algorithm' or cutoff levels between the earlier and present study, so this does not appear to explain this difference. The mean screening blood spot $\mathrm{T} 4$ and serum free T4 and TSH values at diagnosis were not statistically different between those detected on the first versus second NBS test. Thus, infants detected on the second screening test appeared to have the same degree of hypothyroidism as those detected on the first test, albeit with delayed onset. Analysis of blood spot TSH values indicated that those detected on the first screen had a higher chance of having a TSH above $200 \mathrm{mIU} / \mathrm{l}$, but since a different proportion of TSH results above $200 \mathrm{mU} / \mathrm{l}$ were reported on the first screen (actual number), while a higher proportion of TSH results were reported as ' $>200 \mathrm{mIU} / \mathrm{l}$ ' on the second screen, we do not believe that this difference is meaningful.

Gaudino et al. [11] from France reported that on recall examination at the age of 3 years, a third of children with $\mathrm{CH}$ detected on NBS were found to have a normally located (eutopic) thyroid gland by ultrasound, and among these patients, $38 \%$ of cases represented transient hypothyroidism. While we did not undertake thyroid ultrasound or scan in our current study, we speculate that most of the transient cases likely would have a eutopic thyroid gland on imaging.

We found that infants detected on the second NBS test were on a lower l-thyroxine dose at the age of 3 years, consistent with the finding that the majority of patients detected on the second test had transient $\mathrm{CH}$. In a report from Italy by Messina et al. [12] of children with $\mathrm{CH}$ associated with a eutopic gland by ultrasonography, those on a lower l-thyroxine dose at 12 and 24 months ( $<1.7$ and $<1.45 \mu \mathrm{g} / \mathrm{kg} /$ day, respectively) were more likely to have transient hypothyroidism discovered at the age of 3 years, while children with permanent $\mathrm{CH}$ had higher l-thyroxine dose requirements at 12 and 24 months ( $>4.9$ and $>4.27 \mu \mathrm{g} / \mathrm{kg} /$ day, respectively).

Transient versus Permanent $\mathrm{CH}$ in Infants after the Age of 3 Years
We are not aware that NBS programs that collect a single routine specimen have experienced cases that 'passed' their screening test, but then were diagnosed with hypothyroidism in early infancy. Given that our cases detected on the second screen are more likely to be transient, it is possible that these patients may go clinically unrecognized in NBS programs with a single screening test. As infants in our study detected on the second screen have a similar degree of hypothyroidism at diagnosis, we believe that initial treatment and follow-up should be similar to those infants detected on the first NBS test. It may be that these permanent cases are thought to have acquired hypothyroidism, and so they are not reported as 'missed' by single specimen screening programs. The potential benefit of detection of cases on a second screening test needs to be balanced against the expense of collecting two routine specimens. The NWRSP estimates a cost of $\$ 7.71$ (US dollars) to screen each baby for $\mathrm{CH}$ [13]. Thus, the cost to detect each $\mathrm{CH}$ case on the first screen $(1: 1,984)$ is $\$ 15,297$, while the cost to detect $\mathrm{CH}$ via the second screen $(1: 11,438)$ is $\$ 88,187$. Twelve of the 50 states in the United States collect a second routine NBS specimen; the study quoted above by Shapira et al. [8] questioned the cost efficiency (and necessity) of the twoscreen approach.

Including all cases detected on the first and second routine NBS test, we found that 32 of 109 (29.4\%) had transient hypothyroidism. Korzeniewski et al. [14] reported that in a follow-up of $\mathrm{CH}$ cases $>3$ years of age detected on the Michigan NBS program, 25\% of cases had transient hypothyroidism. Infants who were Black, low birth weight, or who required admission to a neonatal intensive care had an increased odds ratio of transient hypothyroidism. Eugster et al. [15] from Indiana, USA, reported that in children $>3$ years of age with $\mathrm{CH}$ without an identified permanent cause, who were trialed off 1 thyroxine therapy, $36 \%$ had transient $\mathrm{CH}$. Excluding identified permanent causes, e.g., thyroid dysgenesis, is likely to lead to a similar higher percentage of transient cases. Gaudino et al. [11] from France reported that 38\% of cases with a eutopic thyroid gland had transient $\mathrm{CH}$. Other studies, however, report a lower percentage of transient CH. Mengreli et al. [16] from Greece reported a rate of transient hypothyroidism of only $11.2 \%$ upon re-evaluation at the age of 3 years. This lower rate may be secondary to the higher TSH cutoff of $20 \mathrm{mIU} / \mathrm{l}$ (whole blood, equivalent to $40 \mathrm{mIU} / \mathrm{l}$ in serum) set by the Greek NBS program, which might miss milder and possibly transient forms of $\mathrm{CH}$. Overall, however, it appears that a significant percentage of children with $\mathrm{CH}$ have a tran-

Horm Res Paediatr 2016;86:169-177 175 
sient requirement for 1-thyroxine replacement. In this context, it is interesting to note that a study using health insurance claims found that one third of children with $\mathrm{CH}$ detected on NBS in the United States discontinued thyroid hormone treatment within 36 months of age [17]. The reason for discontinuation, and whether these children had transient $\mathrm{CH}$ or required continued treatment, was unknown.

Although not a primary aim of our study, we were able to determine whether PCPs are following the current AAP and ESPE guidelines for trialing children without laboratory findings consistent with permanent $\mathrm{CH}$ off thyroid replacement after the age of 3 years $[5,6]$. Approximately $16 \%$ of cases not meeting laboratory criteria for permanent $\mathrm{CH}$ were not trialed off thyroid hormone ('indeterminate') (fig. 1), suggesting that a significant proportion of PCPs are not aware of the guideline recommendations, and that further outreach and education is warranted.

There are limitations to our study. Our large geographic region necessitates follow-up treatment and monitoring of many patients by PCPs. As noted above, we were unable to determine permanent versus transient $\mathrm{CH}$ status after 3 years in $16 \%$ of cases. In addition, thyroid imaging was not part of the routine diagnostic evaluation. Defining thyroid anatomy by imaging at re-evaluation after the age of 3 years, as recommended by the ESPE guidelines [7], and so establishing a more precise etiology, would likely help to explain the differences in percent permanent versus transient $\mathrm{CH}$ detected on the first versus second screen.

In conclusion, infants detected on our second routine NBS have a higher incidence of transient $\mathrm{CH}$, whereas most infants detected on the first NBS have permanent $\mathrm{CH}$. Blood spot screening and serum thyroid function tests for infants detected on the first and second NBS showed a similar degree of hypothyroidism at diagnosis, though infants detected on the second routine screen were maintained on lower 1-thyroxine doses at the age of 3 years. Attempts should be made to ensure that PCPs are aware of implementing guidelines regarding trial off therapy when permanent $\mathrm{CH}$ has not been established. Further study is needed to determine why infants detected on the second screen have a notably different rate of transient versus permanent $\mathrm{CH}$.

\section{Acknowledgment}

Support for Dr. Ford was provided by a US National Institute of Child Health and Human Development (NIH/DHHS) Training Grant in Pediatric Endocrinology (\#2 T32 HD007497-11).

\section{Disclosure Statement}

The authors have no conflicts of interest to disclose.

\section{References}

1 Rastogi MV, LaFranchi SH: Congenital hypothyroidism. Orphanet J Rare Dis Jun 2010;10: 17.

-2 LaFranchi SH: Newborn screening strategies for congenital hypothyroidism: an update. J Inherit Metab Dis 2010;33:225-233.

- 3 LaFranchi S, Hanna C, Krainz P, Skeels M, Miyahira R, Sesser R: Screening for congenital hypothyroidism with specimen collection at two time periods: results of the Northwest Regional Screening Program. Pediatrics 1985; 76:734-740.

4 Maniatis A, Taylor L, Letson GW, Bloch C, Kappy M, Zeitler P: Congenital hypothyroidism and the second newborn metabolic screening in Colorado, USA. J Pediatr Endocrinol Metab 2006;19:31-38.
5 Oakley GA, Muir T, Ray M, Girdwood RWA, Kennedy R, Donaldson MDC: Increased incidence of congenital malformations in children with transient thyroid-stimulating hormone elevation on newborn screening. J Pediatr 1998;132:726-730.

6 American Academy of Pediatrics, Rose SR; Section on Endocrinology and Committee on Genetics, American Thyroid Association, Brown RS; Public Health Committee, Lawson Wilkins Pediatric Endocrine Society, Foley T, Kaplowitz PB, Kaye CI, Sundararajan S, Varma SK: Update of newborn screening and therapy for congenital hypothyroidism. Pediatrics 2006;117:2290-2303.

7 Léger J, Olivieri A, Donaldson M, et al: European Society for Paediatric Endocrinology consensus guidelines on screening, diagnosis, and management of congenital hypothyroidism. J Clin Endocrinol Metab 2014;99:363384.

\footnotetext{
8 Shapira SK, Hinton CF, Held PK, et al: Single newborn screen or routine second screening for primary congenital hypothyroidism. Mol Gen Metab 2015;116:125-132.

-9 Mandel SJ, Hermos RJ, Larson CA, Prigozhin AB, Rojas DA, Mitchell ML: Atypical hypothyroidism and the very low birth weight infant. Thyroid 2000;10:693-695.

$\checkmark 10$ Woo HC, Lizarda A, Tucker R, Mitchell ML, Vohr G, Oh W, Phornphutkul C: Congenital hypothyroidism with a delayed thyroid-stimulating hormone (TSH) elevation in very premature infants: incidence and growth and developmental outcomes. J Pediatr 2011;158: 538-542.

11 Gaudino R, Garel C, Czernichow P, Leger J: Proportion of various types of thyroid disorders among newborns with congenital hypothyroidism and normally located bland: a regional cohort study. Clin Endocrinol 2005;62: 444-448.
} 
12 Messina MF, Aversa T, Salzano G, Zirilli G, Sferlazzas C, De Luca F, Lombardo F: Early discrimination between transient and permanent congenital hypothyroidism in children with a eutopic gland. Horm Res Paediatr 2015;84:159-164.

13 Ford G, LaFranchi SH: Screening for congenital hypothyroidism: a worldwide view of strategies. Best Pract Res Clin Endocrinol Metab 2014;28:175-187.
14 Korzeniewski SJ, Grigorescu V, Kleyn M, Young WI, Birbeck G, Todem D, Romero R, Panseth N: Transient hypothyroidism at 3-year follow-up among cases of congenital hypothyroidism detected by newborn screening. J Pediatr 2013;162:177-182.

15 Eugster E, LeMay D, Zerin M, Pescovitz O: Definitive diagnosis in children with congenital hypothyroidism. J Pediatr 2004;144:643647.
6 Mengreli C, Kanaka-Gantenbein C, Girginoudis P, Magiakou MA, Christakopoulou I, Giannoulia-Karantana A, et al: Screening for congenital hypothyroidism: the significance of threshold limit in false-negative results. J Clin Endocrinol Metab 2010;95:4283-4290.

7 Kemper AR, Ouyang L, Grosse SD: Discontinuation of thyroid hormone treatment among children in the United States with congenital hypothyroidism: findings from health insurance claims data. BMC Pediatrics 2010; 10:9. 